\title{
Betablocker Use in Cerebral Proliferative Angiopathy: Case Report
}

\section{Glaucia Suzanna Jong A Liem ${ }^{1}$, Fernando Mendes Paschoal Junior ${ }^{2}$, Feres Eduardo Aparecido Chaddad Neto $^{3}$, Eberval Gadelha Figueiredo ${ }^{4}$, Manoel Jacobsen Teixeira ${ }^{4}$, Edson Bor-Seng-Shu ${ }^{4}$ and Eric Homero Albuquerque Paschoal ${ }^{1,2,4^{*}}$}

${ }^{1}$ Department of Neurosurgery, Hospital Ophir Loyola, Pará, Brazil

${ }^{2}$ Department of Neurology, Hospital da Aeronáutica de Belém, Pará, Brazil

${ }^{3}$ Department of Neurosurgery, Hospital São Paulo, Universidade Federal de São Paulo, São Paulo, Brazil

${ }^{4}$ Department of Neurosurgery, Hospital das Clínicas de São Paulo, São Paulo, Brazil

*Corresponding author: Eric HA Paschoal, Department of Neurosurgery, Hospital Ophir Loyola, Pará, Brazil; Department of Neurology, Hospital da Aeronáutica de Belém, Pará, Brazil; Department of Neurosurgery, Hospital das Clínicas de São Paulo, São Paulo, Brazil, Rua Municipalidade, 985. Office 1905/2105, Postal code: 66-050-350, Brazil

\begin{abstract}
We describe a case of cerebral proliferative angiopathy in a patient with frequent episodes of disabling headaches. The clinical details, radiographic and angiogram findings and medical management are reviewed. This is the first described cerebral proliferative angiopathy case in which we noticed shrinkage of a vascular lesion with the use of a betablocker.
\end{abstract}

\section{Keywords}

Cerebral proliferative angiopathy, Chronic ischemia, Betablocker, Headache

\section{Case Description}

A 29-year-old young man attended the neurosurgery outpatient clinic with a chief complaint of headache, mild cognitive impairment, and intermittent left upper limb paraesthesia. A contrast-enhanced MRI of the brain initially showed a tangling of vessels in the region of the basal ganglia bilaterally, suggesting vascular shunts. Nutrition was noted mainly from the posterior cerebral arteries and the drainage directed to the vein of Galen and the superior sagittal sinus - suggesting an occlusive cerebrovascular disease. This study was complemented with a cerebral angioresonance where the vascular tangles were best described as a network of severe vascular ectasias with multiple small intracranial aneurysms sparse across the brain - compromising the basal ganglia, the basal cisterns, the polygon vessels, and the ventricular system - suggesting a complex arteriovenous malformation (AVM) or Moya-Moya disease.

For a better elucidation of the case, the patient was submitted to an angiographic study where a vast vascular tangle was noted, interspersed with a functioning parenchyma with characteristics like those described by the neuroradiologist Lasjaunias, et al. [1]

Considering the extension, depth, high surgical risk, and oligosymptomatic clinical picture - the medical team opted for a regular clinical-radiological follow-up with the introduction of symptomatic medications.

Further during outpatient follow-up, the patient mainly complained of frequent hemicrania headache attacks associated with paraesthesia and transient loss of motor strength in the left side. Pain that most of the time resembled a condition of migraine and that was not completely relieved with simple painkillers. Hence why, $10 \mathrm{mg}$ of Nortriptyline and $80 \mathrm{mg}$ of Propranolol was introduced for the prophylactic treatment of migraine-like headache, in addition to Triptans if the

Citation: Liem GSJA, Junior FMP, Neto FEAC, Figueiredo EG, Teixeira MJ, et al. (2022) Betablocker Use in Cerebral Proliferative Angiopathy: Case Report. Neurosurg Cases Rev 5:097. doi.org/10.23937/26434474/1710097

Accepted: February 08, 2022; Published: February 10, 2022

Copyright: (c) 2022 Liem GSJA, et al. This is an open-access article distributed under the terms of the Creative Commons Attribution License, which permits unrestricted use, distribution, and reproduction in any medium, provided the original author and source are credited. 


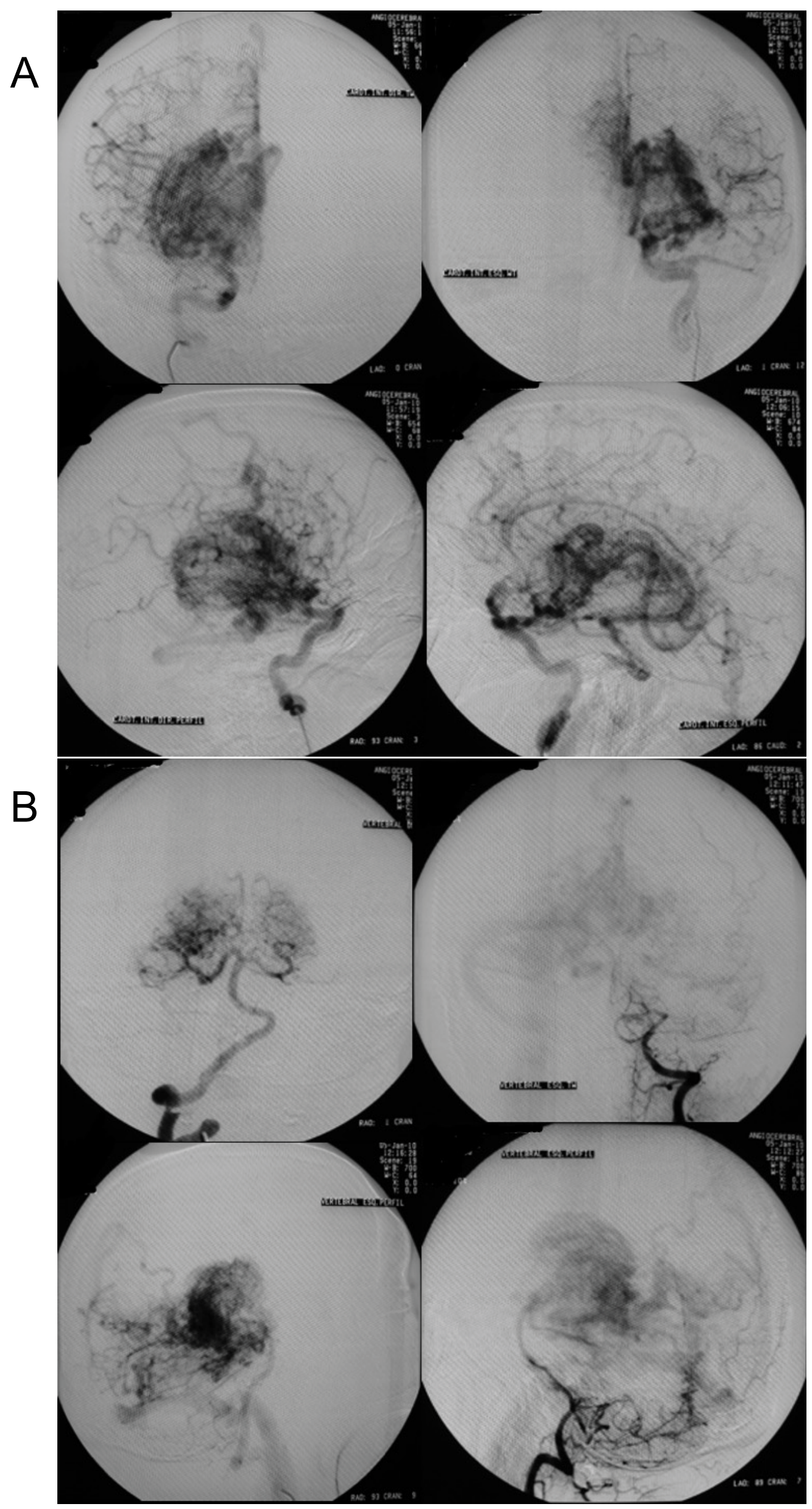

Figure 1: The first cerebral angiography of a 29-year-old young man attended the neurosurgery outpatient clinic with a chief complaint of headache, mild cognitive impairment, and intermittent left upper limb paraesthesia (a) Anterior circulation; (b) Posterior circulation. 
patient presented severe incapacitating attacks. Since then, the patient presented with progressive control of the headache attacks and no signs of collateral effects, therefore, propranolol was maintained.

Seven years later, a control cerebral arteriography was performed, which showed shrinkage of the vascular network and an apparent improvement in the anomalous cerebral flow that caused chronic perinidal oligemia.

\section{Discussion}

Proliferative cerebral angiopathy (CPA) is a rare clinical entity and was recently described by a French neuroradiologist Lasjaunias, et al. [1]. It is formed by a diffuse vascular network that characteristically presents a functional brain parenchyma permeating it [2]. This entity is different from arteriovenous malformations (AVM) due to its clinical, angiographic, and pathophysiological characteristics. In the literature, we found just under 100 cases described, of which half were in the pioneer study [1,3].

The most common clinical manifestations include headache $(44.9 \%)$, seizures $(37.1 \%)$ and transient ischemic attacks (33.7\%) [3]. Unlike AVM, it is noted that CPA has a lower relative risk of spontaneous bleeding (18\%). Studies suspect that proliferative pathophysiology involves adaptive arterial recruitment associated with the process of angiogenesis induced by chronic tissue hypoperfusion [4-6].
To date, the treatment of this clinical entity is still widely discussed and controversial. As the intermingled and surrounding healthy brain tissue are at risk of ischemia if even partially embolized [1]. Most reported cases are managed conservatively with a close outpatient follow-up: regular imaging, aside the use of symptom relievers [7].

The case described in this paper is about a young man with CPA who, at first, complained of headache with migraine characteristics without aura. Crises became more and more frequent and disabling. According to international protocols for the treatment of headache, the prophylactic treatment of migraine with tricyclics and beta-blockers is recommended [8-10]. During outpatient follow-up, the good therapeutic response to the medications was notorious, with a reduction in the frequency and intensity of migraine attacks.

During the outpatient follow-up, a new control angiography was performed, seven years after the first, in which major changes in the vasculature with shrinkage of the lesion were found. Considering that the patient did not undergo any invasive treatment and did not use any other drug treatment, the biggest suspect in the result of the new arteriography would be the use of beta-blockers.

This beta-blocker, more specifically propranolol, is widely studied and used in infantile haemangioma, in which it acts as a VEGF inhibitory agent. This, in turn,

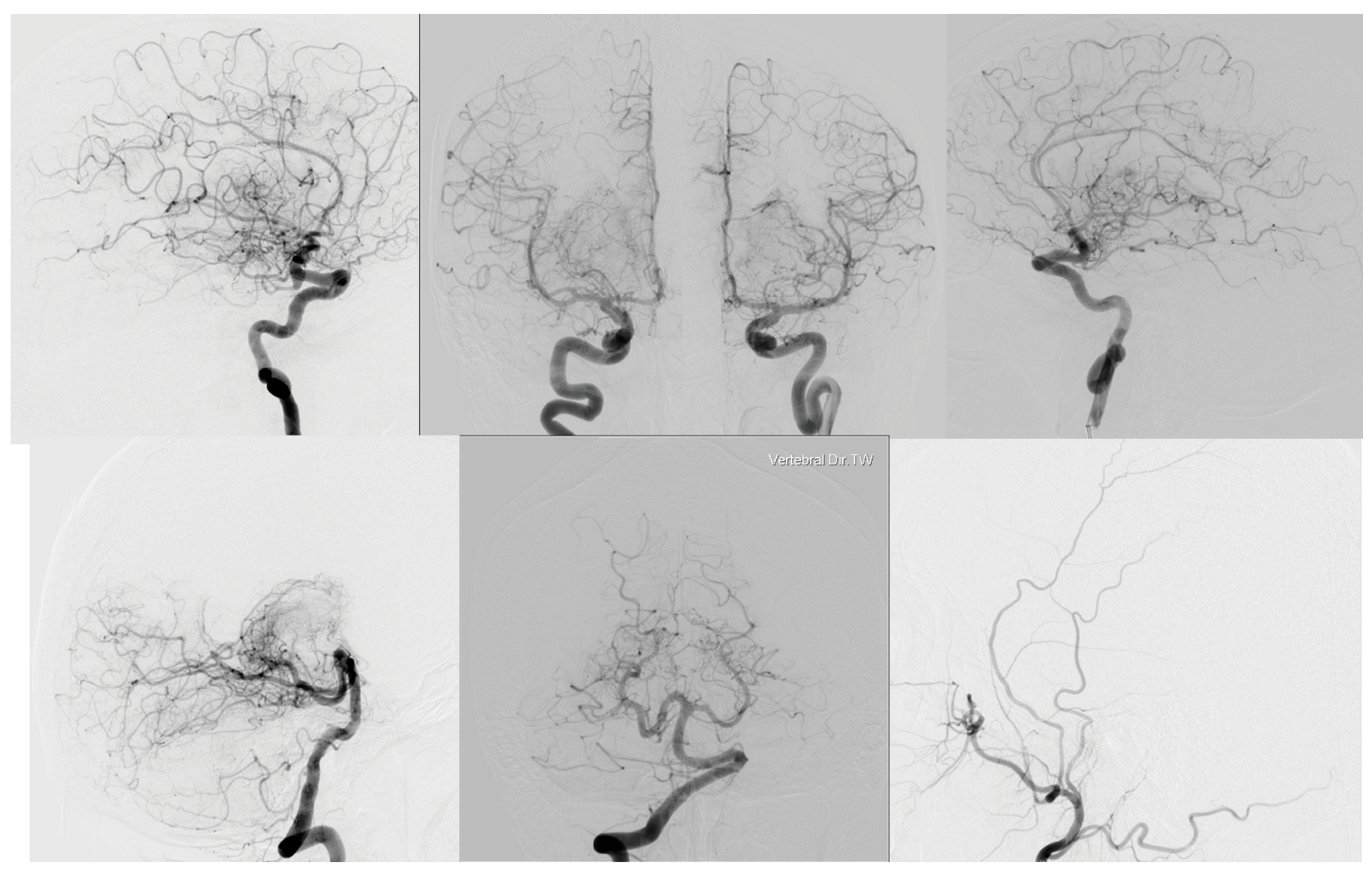

Figure 2: The control cerebral angiography of the same patient after taking betablockers to prevent migraine-like headaches. 
is a master regulator of angiogenesis. Experimental studies have shown that propranolol has a cytotoxic and antiproliferative effect on stem and endothelial cells, thus also affecting the perivascular cell contraction of infantile haemangioma - thus leading to lesion regression, and often avoiding surgical procedures $[11,12]$.

There are some studies that have also demonstrated the efficacy of propranolol on cerebral cavernomas of familial presentation that are difficult to access surgically [13]. At the moment, a randomized controlled trial is to define the effect of propranolol on these lesions [14].

Similarly, could propranolol, then, be a causative agent of CPA regression? Studies with a higher level of evidence will need to be carried out to take this as true and as a therapeutic or adjuvant method for cases of CPA. For the time being, we maintain a conservative approach in most cases with regular clinical and radiological follow-up (Figure 1a, Figure $1 b$ and Figure 2).

\section{Declaration of Interest}

The authors report no declarations of interest. The authors alone are responsible for the content and writing of the paper.

\section{References}

1. Lasjaunias PL, Landrieu P, Rodesch G, Alvarez H, Ozanne A, et al. (2008) Cerebral proliferative angiopathy: Clinical and angiographic description of an entity different from cerebral AVMs. Stroke 39: 878-885.

2. Kono K, Terada T (2014) Encephaloduroarteriosynangiosis for cerebral proliferative angiopathy with cerebral ischemia. J Neurosurg 121: 1411-1415.

3. Yamaki VN, Solla DJF, Telles JPM, Liem GLJ, da Silva SA, et al. (2020) The current clinical picture of cerebral proliferative angiopathy: Systematic review. Acta Neurochir (Wien) 162: 1727-1733.
4. Ducreux D, Meder JF, Fredy D, Bittoun J, Lasjaunias P (2004) MR perfusion imaging in proliferative angiopathy. Neuroradiology 46: 105-112.

5. Ducreux D, Petit-Lacour MC, Marsot-Dupuch K, Bittoun $J$, Lasjaunias $P(2002)$ MR perfusion imaging in a case of cerebral proliferative angiopathy. Eur Radiol 12: 27172722.

6. Vargas MC, Castillo M (2011) Magnetic resonance perfusion imaging in proliferative cerebral angiopathy. $\mathrm{J}$ Comput Assist Tomogr 35: 33-38.

7. Liu P, Lv X, Lv M, Li Y (2016) Cerebral proliferative angiopathy: Clinical, angiographic features and literature review. Interv Neuroradiol 22: 101-107.

8. Goadsby PJ, Lipton RB, Ferrari MD (2002) Migraine-current understanding and treatment. N Engl J Med 346: 257-270.

9. Silberstein SD, Holland S, Freitag F, Dodick DW, Argoff $C$, et al. (2012) Evidence-based guideline update: Pharmacologic treatment for episodic migraine prevention in adults: Report of the quality standards subcommittee of the american academy of neurology and the american headache society. Neurology 78: 1337-1345.

10. Steiner TJ, Jensen R, Katsarava Z, Linde M, MacGregor $E A$, et al. (2019) Aids to management of headache disorders in primary care (2nd edition): On behalf of the european headache federation and lifting the burden: The global campaign against headache. J Headache Pain 20: 57.

11. Lee JC, Modiri O, England RW, Shawber CJ, Wu JK (2021) Propranolol therapy in infantile hemangioma: It is not just about the beta. Plast Reconstr Surg 147: 875-885.

12. Rotter A, de Oliveira ZNP (2017) Infantile hemangioma: Pathogenesis and mechanisms of action of propranolol. $J$ Dtsch Dermatol Ges 15: 1185-1190.

13. Apra C, Dumot C, Bourdillon P, Pelissou-Guyotat I (2019) Could propranolol be beneficial in adult cerebral cavernous malformations? Neurosurg Rev 42: 403-408.

14. Lanfranconi S, Scola E, Bertani GA, Zarino B, Pallini R, et al. (2020) Propranolol for familial cerebral cavernous malformation (Treat_CCM): Study protocol for a randomized controlled pilot trial. Trials 21: 401. 